\title{
The Feasibility of Establishing Folk Sports Course in Hebei Provincial Tertiary Schools
}

\author{
Haixia Gan \\ Physical Education Department of Hebei University, Baoding 071002, China \\ Xinzhong $\mathrm{Gu}$ \\ School of Medical Education, HeBei University, Baoding, China \\ Fuqing Yang \\ Department of College English Teaching and Research, Daoding, China
}

\begin{abstract}
Rich and colorful folk sports exist in Hebei Province, but many are not well promoted and developed. In response to the call of "implementation of the nationwide body-building plan" to achieve new and rapid breakthroughs in the development of mass sports, this study is going to research the feasibility of introducing folk sports courses into universities and colleges in Hebei province, hoping to improve the effect of PE teaching and education in tertiary schools, meantime to lay a theoretical foundation for promoting the development of folk sports.
\end{abstract}

KEYWORDS: Folk sports; Tertiary school PE education; Curriculum reform; Feasibility

\section{INTRODUCTION}

In the incubation of the Yanzhao culture, the colorful and various provincial folk sports are characterized of national Yanzhao culture. According to the statistics of "Chinese folk traditional sports records", there are more than 1000 folk sports items all around the nation, among which, the provincial items are more than 100, accounting for $10 \%$ of the total national folk sports. In history, Hebei province has long been the fertile soil and holy land for the prosperous development of folk sports culture. To fully develop the provincial folk sports and spread them both abroad and domestically, offering folk sports courses in tertiary PE education, without doubt, is the best way out. What is more, the prosperous development of the folk sports may also benefit the cultural development of Hebei province, benefit the folk and mass population of Hebei province.

\section{PRESENT SITUATION OF THE FOLK SPORTS IN HEBEI PROVINCE}

Folk sports in Hebei province has long been practiced and developed among the civil liberties and folk people. It is free from the restrict of time, site, staff and forms, which makes it easily and naturally linked to people's daily life. During its evolution and development, various sorts of items have emerged, especially the martial arts, kite flying and acrobatics are world-famous. They have become not only a vivid reflection of the diversity of Chinese culture, but also the irreproducible intangible cultural heritage among the Chinese folk people.[1] Though colorful with more varieties, they disperse among the folk people. Without effective guidance, it is not easy to form a cultural climate, neither easy to transmit and get fully developed. Because many forms are not widely spread, few people can take part.

\section{FEATURES OF THE FOLK SPORTS}

\subsection{Regional and local limitations}

All ethnic groups in Hebei province are good at singing and dancing, riding and shooting. They love exchanging culture and sports. The mutual exchanges help promote the continuous development of the traditional culture and traditional sports, forming some traditional sports with the unity of sports skills and artistic beauty, which can not only build the physical health but also improve the mental pleasure, achieving the harmonious integration of health, strength and beauty. These traditional sports are developed from the ethnic social life, with the characteristics of ethnic features, they are mainly functioning as fitness, self-defense, and entertainment. Most often, the traditional folk sports are rich in long history and moving legendary story, beautiful colors and unique tastes, reflecting the customs, cultural features, ethics and religious 
beliefs of different ethnic groups. The folk sports have become a special form of the political and cultural life of the civil people.[2]

Geographically, Hebei province is located in the North China Plain, across the Inner Mongolia Plateau, with the capital city Beijing and Tianjin inside. To its north, is the Yan Mountains, to its west is the great TaiHang Mountains, while to its east lies the Bohai sea which is rich in resources. Due to the sharp differences in natural environment, the sports culture is characterized of strong regional features. For example, in the districts of Zhangjiakou and Chengde, such ethnic groups as Mongolian, Manchu, Hui and other multi-ethnic groups mix together, they have developed some typical sports items like horse racing, pearl collecting, bride chasing, and buzkashi. While in Caozhou district, traditional martial arts and acrobatics are world famous. However, shuttlecock playing is popular in Baoding district, and gymnastic ball is widely played in Wuji district.

\subsection{National and folkloric features}

Traditional sports and the different customs are closely related, mutually penetrated into each other, forming the nationalism of the folk sports. On one hand, folk customs promote the further development of traditional sports, on the other, traditional sports enrich the content of folk customs. Some traditional sports are integrated into the traditional festivals, wedding celebrations, and other kinds of festivals, while meantime, some traditional festivals and celebrations contain sports items.[3]

In many traditional festivals, we can easily find the elements of entertainment and folk sports activities. For example, the Dragon Boat Festival originally is celebrated to commemorate the poet $\mathrm{Qu}$ Yuan. People not only eat rice dumplings, drink realgar wine, but also take part in a wide variety of sports activities, such as the Mongolian Nadam fire for ethnic group of Mongolia, horse racing among the Nuchen Nationality. Another example is the July fifteen "Dawei call" among the Manchu people. The integration of folk sports into traditional festivals enables the festivals to be more entertaining, more enjoyable, fully meeting the needs of most people.

\subsection{Playful and interesting characteristics}

Originally, the folk and traditional sports were mostly taken when people were not busy, for the purpose of celebrating harvests, festivals, weddings and entertaining. People inject sports into recreation and entertainment in order to expand the cheerful atmosphere.

To play games is human nature, gestating human culture. Games can make people forget the difference in their identity, hierarchy and superiority. Games constitute the important part in folk sports, with playfulness as one of the most important characteristics of Chinese folk sports. Many sports are played in the form of games, such as playing shuttlecock, playing ice GA, spinning a top, catching the old kiln, swinging, flying a kite, and backing the elder brother, etc. None of the participants, no matter what is his intelligence, capability, financial abilities, or his social status, before the activities, would like to admit that he is no better than the others. For most of the folk sports, their playfulness is indicated in the following aspects that the participants will win the games by using their physical strength and playing skills. For example, in the games of pushing siderosphere, archery, horse racing, and stone ball kicking, the two sides will compete with each other in their physical strength, intelligence and skills, it is difficult for them to have a lucky chance of winning.

\section{FEASIBILITY OF ESTABLISHING FOLK SPORTS COURSE IN HIGHER EDUCATION}

\subsection{The school Physical Education is qualified to meet the needs of folk sports.}

It can not be ignored that one of the important channels of the transmission of folk sports is through school PE education, whose special role is to educate, inherit and carry forward the traditional culture.[4] For quite a long time, not much importance has been attached to folk sports in various ranks of schools especially in tertiary schools. As a matter of fact, folk sports should become one part of the sports curriculum because unlike other sports, most of the folk sports items require less for the equipments and facilities. They are applicable, easy to carry out, most suitable for the students to participate in.

\subsection{It conforms to the guiding ideology of college Physical Education.}

"The decision of further promote quality education" issued by the CPC Central Committee and the State Council established the guiding ideology that "Health First" is the most important purpose of physical education. Compared with the fitness philosophy of western competitive sports, Chinese traditional folk sports has a special advantage in search of the essence of life, the harmony between man and nature, and self-cultivation, which can tap the essence of sports service for health more than the western competitive sports. In school education, college is the last station to cultivate lifelong sports for students, it is quite necessary to offer some optional courses to introduce the interesting and playful folk sports items in order to mobilize and attract more students to engage in sports. Many folk sports items require participants to have strong ability of coordination and team spirit, which can 
improve the comprehensive quality of students. When the students spread and transmit the skills of folk sports to their family and friends and peers, even more people will participate into sports activities, hence to strengthen and improve the whole nation's physical health and cultural accomplishment.

\section{SUGGESTIONS ON THE FOLK SPORTS COURSES}

Hebei province is rich in folk sports, but they disperse among the folk people without being fully applied and developed. There is still a large room to develop the folk sports as part of curriculum resources. How to better develop, organize and utilize folk sports curriculum resources, how to refine them to become the essence of national traditional sports, and make them widely spread in universities and colleges, will become the focus for future studies.

\subsection{The selection of folk sports items}

Choose the traditional sports which suit college physical education teaching. Make a full study and analysis of the folk sports from the aspects of their regional characteristics, seasonal playfulness, fitness value and human value, choose those interesting items that require less for the sports venues and equipments, require less for the students but with good training effect, then adapt, restructure and standardize the course content and curriculum, making it easy to spread among college students. [5]

\subsection{The cultivation of teaching staff}

Teaching staff plays an essential role in teaching and educational reform. More and better teachers will be required if folk sports courses are started in higher schools. We can enroll professional teachers from the national school, or send the young teachers out to be trained. We still can invite experts to deliver lectures, or invite the folk sports experts to tutor the in-school sports teaching. Anyway, a variety of ways can be adopted to improve the teachers' theoretical and practical ability of folk sports in carrying out the sports curriculum in universities.

\subsection{The spread of folk sports}

Strengthen the spread and transmission of folk sports culture is of the same importance. Among the folk sports curriculum, special stress should be placed on the teaching of the cultural values and characteristics of the sports items. If students are interested in the folk sports, they will have much knowledge and deep understanding about them, and they will be absorbed into learning them, teaching them, and spreading them to the other people. Alternative ways can be adopted to spread the folk culture. For example, folk sports artists can be invited to give performance, in order to arouse the students' interests and participation into the exercise of the sports.

\section{REFERENCES}

[1] T. C. Fei, C. Z. Dan and Y. Wei, Concepts and mutual relations of sports in folk, traditional sports, folk sports and minority sports, Journal of Wuhan Institute of Physical Education, vol.41, pp. 24-31,2007.

[2] C. Li, Analysis of The Character of Folk- custom Physical Cultute and Realistic Affection, Journal of Wuhan jiline of Physical Education, vol.3, pp. 5-7, 2006.

[3] F. Meng, Folk sport Value of National Traditional Festival in China, China Sport Science and Technology, vol.5, pp. 34-37, 2006

[4] S.L. Ling and L. Wei, A Study on the Associated Development between Folk Sports and School Sports, Journal of huaihai Institute of Technology, vol. 2, pp. 107109, 2003.

[5] M. F. Nian, Z. q. Hong and C. Qing, A Reesearch on the Measures for the Exploitation of the Traditional Ethnic and Folk Physical Cultural Resources and Their Entry into School Physical Education, Journal of Capital Institute of Physical Education, vol. 18, pp. 38-39, 2006. 